\title{
Orthogonally polarized RF and microwave equalizers and single sideband generators based on Kerr microcombs
}

David Moss ${ }^{1}$

${ }^{1}$ Affiliation not available

December 6, 2021

\section{Hosted file}

Ring Resonator Single Sideband J Sem authorea.pdf available at https://authorea.com/users/ 418067/articles/548067-orthogonally-polarized-rf-and-microwave-equalizers-and-singlesideband-generators-based-on-kerr-microcombs 